\title{
Anatomical Properties and Near Infrared Spectra Characteristics of Four Shorea Species from Indonesia
}

\author{
Danang Sudarwoko Adi ${ }^{*}$, Sung-Wook Hwang ${ }^{2}$, Dwi Ajias Pramasari', Yusup Amin', Hairi Cipta ${ }^{3}$, Ratih Damayanti ${ }^{4}$, \\ Wahyu Dwianto ${ }^{1 *}$, Junji Sugiyama ${ }^{2,5}$ \\ ${ }^{1}$ Research Center for Biomaterials, Indonesian Institute of Sciences, Cibinong Science Center, Bogor, Indonesia \\ ${ }^{2}$ RISH, Kyoto University, Gokasho, Uji, Kyoto, Japan \\ ${ }^{3}$ Gadjah Mada University, Yogyakarta, Indonesia \\ ${ }^{4}$ Forest Product Research and Development Center, Indonesian Ministry of Environment and Forestry, Bogor, Indonesia \\ ${ }^{5}$ College of Materials Science and Engineering, Nanjing Forestry University, Nanjing, China
}

ARTICLE INFO

Article history:

Received October 10, 2019

Received in revised form June 1, 2020

Accepted June 14, 2020

\section{KEYWORDS:}

Shorea wood,

Near-infrared,

Anatomical properties,

PCA, k-NN

\begin{abstract}
This study investigated the anatomical properties and absorbance characteristics of NIR spectra of four Shorea species from Indonesia. Macroscopic section revealed that Balau has similarity with Heavy Red Meranti, whereas White Meranti was almost identical with Light Red Meranti. All of the woods have diffuse porous and axial resin canals in tangential lines at the microscopic level. Original NIR spectra of Shorea species showed different absorbance characteristic. Wood density was assumed to be one of the factors that affected to the absorbances. Principal component analysis (PCA) of second derivative NIR spectra at the wavenumber $8,000-4,000 \mathrm{~cm}^{-1}$ (full) and $6,200-5,600 \mathrm{~cm}^{-1}$ (specific) showed different orientation among the Principal Component (PC) number. PC1, which contained highest spectral variation, had two closed clusters (1) Balau and Heavy Red Meranti and (2) White and Light Red Meranti at full spectral range. In contrast, the results at specific range were (1) Balau and White Meranti and (2) Heavy and Light Red Meranti. Hierarchical clustering dendrogram using PCA data from two spectral regions resulted in two types of clustering, the 8,000-4,000 $\mathrm{cm}^{-1}$ was somehow related to 'density', while the $6,200-5,600 \mathrm{~cm}^{-1}$ was grouped in 'color' information from visual inspection. From both spectral regions, k-nearest neighbour (k-NN) classification models revealed $100 \%$ accuracy in identification four Shorea species using NIR spectra.
\end{abstract}

\section{Introduction}

Shorea wood, well known as "Meranti", is one of the important timber trade in Indonesia, with about $10 \%$ of the total volume of wood log production (Statistics of Forestry Production 2017). It is classified as the first group of the commercial wood due to its high economic value and categorized into 6 main timber trade groups such as Yellow Meranti, White Meranti, Red Meranti, Balau, Red Balau, and Bangkirai (Decree of The Minister of Forestry 2003). There are many species which are included in each group. For instance, Red Meranti has around 15 species, like Shorea uliginosa, S. parfivolia, S. leprosula, S. selanusa, S. palembanica (Martawijaya et al. 2005). In addition, genera of Shorea consists of 194 species, which is

* Corresponding Author

E-mail Address: danang@biomaterial.lipi.go.id distributed from Sri Lanka and India through IndoChina towards Malesia (Soerianegara and Lemmens 1994). In Indonesia, it is common to use a local name in the wood market. In addition, the name is also based on the weight of the wood. For example, Red Meranti has two major names, which are called Light and Heavy Red Meranti (Soerianegara and Lemmens 1994). The difference between these two groups is the density of wood.

It is common that wood of different species may vary widely in appearance, such as color, texture, and figure. There are also variability in the cell patterns produced by different combinations and factors like size, arrangement, and alignment, (Panshin and de Zeeuw 1980). These properties, which generally called anatomical properties, are important to distinguish and identify the wood species. However, there are also possibilities that some species may have 
similarity of these features. For instance, (Hwang et al. 2016) revealed that Pinus densiflora for. erecta and Pinus silveris have similar anatomical features, thus it was difficult to determine the differences between two species.

Identification of Indonesian Shorea species still used conventional approaches, such as uses macroscopic and microscopic methods to see the anatomical features. Since they come from the same genera, some species of Shorea may have identical anatomical properties, therefore distinguish of each species is challenging. Moreover, traditional methods for wood identification are time and labour consuming because they include the use of physical, anatomical, and visual inspections (Yang et al. 2015). Therefore, the application of the other technique for Shorea identification is also required to obtain the result faster and simple.

One of the other method for wood identification is using near infrared (NIR) spectroscopy. This technique with an aid of chemometrics is useful not only for quantification but also for qualification (Tsuchikawa and Kobori 2015). NIR spectroscopy utilizes the spectral range of near infrared between $12,820 \mathrm{~cm}^{-1}$ and $4,000 \mathrm{~cm}^{-1}$ in wavenumber or 780 and 2,500 $\mathrm{nm}$ in wavelength (Schwanninger et al. 2011), where overtone vibration of functional groups are observable. Application of the NIR spectra for wood discrimination or classification has been successful to distinguish the difference between species (Tsuchikawa et al. 2003; Pastore et al. 2011; Yang et al. 2015; Abe et al. 2016; Lang et al. 2017; Ramalho et al. 2018; Ma et al. 2019). Furthermore, this technique also provides good results to distinguish species in the same genera (Gierlinger et al. 2004; Espinoza et al. 2012; Horikawa et al. 2015; Hwang et al. 2016).

In this study, four wood species from similar genera of Shorea, which are common in Indonesia's wood market, were investigated to distinguish the anatomical properties and to know the appearance of these wood species to the NIR spectra. In Indonesia timber trade, every local group names of the wood such as Red Meranti, White Meranti, and Balau have different prices and qualities. Furthermore, identification of the sawn wood in the market is a problematic for the consumers because due to weathering and other factors wood decolorization makes identification more complicated. In such situations, the aimed of this study was to show the benefit of NIR technique for wood identification in the genera of Shorea in comparison with the commonly method.

\section{Materials and Methods}

\subsection{Materials}

This study used four Shorea species, which were taken from wood collection in Xylarium BogorienseIndonesia. The local timber trade names are Heavy Red Meranti, Light Red Meranti, White Meranti, and Balau. All of the wood samples were in the genera of Shorea. Eleven wood blocks were prepared from each species to obtain the NIR spectra and microscopy samples, where the size of the wood blocks was $2 \mathrm{x}$ $2 \times 2 \mathrm{~cm}$, in longitudinal (l), tangential (t) and radial $(\mathrm{r})$ respectively. In addition, the average wood density was also determined for each species based on the wet volume (Miranda et al. 2011).

\subsection{Anatomical Analysis}

Microscopic sections were used to observe the anatomical features. Wood sections were cut in tangential, radial and cross section by a sliding microtome, with a thickness of $15 \mu \mathrm{m}$. The sections were stained with safranin solution, followed by dehydration with graded ethanol series, and finally mounted on the glass slides. Then, the image of each section were captured with a light microscope (Olympus BX-51) equipped with digital camera (Olympus DP 73). In addition, the stereo micrographs of the cross section were also obtained. Identification under the microscopy level was conducted based on the IAWA list for hardwood species (Wheeler et al. 1989).

\subsection{Near-Infrared Spectroscopy Analysis}

The longitudinal-radial (LR) of wood blocks were subjected to obtain the near-infrared (NIR) spectra (Perkin Elmer Spectrum 100N). Both sides of the LR face were scanned. In average, 22 spectra were measured from each species. The spectra were collected at the wavenumber of $10,000-4,000$ $\mathrm{cm}^{-1}$ with a spectral resolution of $16 \mathrm{~cm}^{-1}$, and 32 scans per each record process. The original spectra were second derivatived by Savitzky-Golay filter smoothing to nine points with third order function (Savitzky and Golay 1964). For principal component analysis, the spectral region over $8,000 \mathrm{~cm}^{-1}$, which was considered to be non-informative due to noise, was excluded from the analysis. 


\subsection{Multivariate Data Analysis and Classification Models}

In principal component analysis (PCA), a total of 20 partial spectral regions were tested to investigate the selective effects of the NIR spectra as well as the full length of $8,000-4,000$ $\mathrm{cm}^{-1}$. An unsupervised hierarchical clustering was performed by the agglomerative Ward's minimum variance method. It was shown as a dendrogram to represent the numerical distances between the data. The classification of the four Shorea species were conducted with k-nearest neighbour (k-NN) algorithm. The training and test sets were randomly selected at a ratio of 0.75 to 0.25 , respectively. All programming related to NIR spectrometric analysis, including data processing and PCA, was done by Python version 3.7.

\section{Results}

\subsection{Anatomical Properties}

Figure 1 showed the macroscopic and microscopic features of White Meranti. Anatomical observation based on the IAWA standard for hardwood species revealed that the wood has characteristics as follows: 2. Growth ring boundaries indistinct or absent; 5 . Wood diffuse-porous; 7. Vessels in diagonal and/ or radial pattern; 43 . $\geq 200 \mu \mathrm{m}$ (mean tangential diameter of vessel lumina); 44. $207 \pm 22 \mu \mathrm{m}$ (mean tangential diameter of vessel lumina); $46 . \leq 5$ vessels per square millimeter; 79. Axial parenchyma vasicentric; 80. Axial parenchyma aliform; 82. Axial parenchyma winged-aliform; 83. Axial parenchyma confluent; 92. Four (3-4) cells per parenchyma strand; 97. Ray width 1 to 3 cells; 98. Larger rays commonly 4- to 10 -seriate; 102 . Ray height $>1 \mathrm{~mm}$; 104. Body ray cells procumbent with one row of upright and/or square marginal cells; 105. 4-12 / $\mathrm{mm}$ (Rays per $\mathrm{mm}$ ); 128 . Axial resin canals in long tangential lines.

Anatomical features on Figure 2 showed that the characteristics of Light Red Meranti were: 2. Growth ring boundaries indistinct or absent; 5 . Wood diffuseporous; 7. Vessels in diagonal and/or radial pattern; 9. Vessels exclusively solitary (90\% or more); $42.100-$ $200 \mu \mathrm{m}$ (Mean tangential diameter of vessel lumina); 44. $162 \pm 37 \mu \mathrm{m}$ (Mean tangential diameter of vessel lumen); 47. 5-20 vessels per square millimeter; 79. Axial parenchyma vasicentric; 80 . Axial parenchyma aliform; 92. Four (3-4) cells per parenchyma strand; 97. Ray width 1 to 3 cells; 104 . 4-12/mm (Rays per $\mathrm{mm}) ; 127$. Axial resin canals in long tangential lines; 128. Axial canals in short tangential lines.

Figure 3 shows the anatomical properties of Heavy Red Meranti. The features shows that the characteristics were: 2. Growth ring boundaries indistinct or absent; 5. Wood diffuse-porous; 7. Vessels in diagonal and/or radial pattern; 43. $\geq 200$ $\mathrm{m}$ (Mean tangential diameter of vessel lumina); 44 . $307 \pm 42 \mu \mathrm{m}$ (Mean tangential diameter of vessel lumina); 46 . $\leq 5$ vessels per square millimeter (Vessel per square millimeter); 79. Axial parenchyma vasicentric; 86 . Axial parenchyma in narrow bands or lines up to three cells wide; 93. Eight (5-8) cells per parenchyma strand; 98 . Larger rays commonly 4- to 10-seriate; 97 . Ray width 1 to 3 cells; 103 . Rays of two distinct sizes; 102 . Ray height $>1 \mathrm{~mm} ; 104$. $\leq 4 / \mathrm{mm}$ (Rays per $\mathrm{mm}$ ); 127. Axial canals in long tangential lines; 128. Axial canals in short tangential lines.

Figure 4 showed the anatomical features of Balau. It shows that this species has: 2 . Growth ring boundaries indistinct or absent; 5 . Wood diffuseporous; 7. Vessels in diagonal and/or radial pattern; 10 . Vessels in radial multiples of 4 or more common; 42. 100-200 $\mu \mathrm{m}$ (Mean tangential diameter of vessel lumina); 44. 183 $\pm 35 \mu \mathrm{m}$ (Mean tangential diameter of vessel lumina); 47. 5-20 vessels per square millimeter; 79. Axial parenchyma vasicentric; 82. Axial parenchyma winged-aliform; 93. Eight (5-8) cells per parenchyma strand; 97. Ray width 1 to 3 cells; 98. Larger rays commonly 4- to 10-seriate; 104. 4-12/mm (Rays per $\mathrm{mm}$ ); 128. Axial canals in short tangential lines.

\subsection{NIR Spectra Analysis}

Figure 5 showed the original spectra of Shorea woods. The response of those species to the NIR absorbance was difference. It was clearly seen that the highest absorbance was Balau, followed by Heavy Red Meranti, White Meranti, and Light Red Meranti, respectively. However, the differences of original spectra among these species were almost similar, thus, it was difficult to distinguish the important peak of wood samples. 

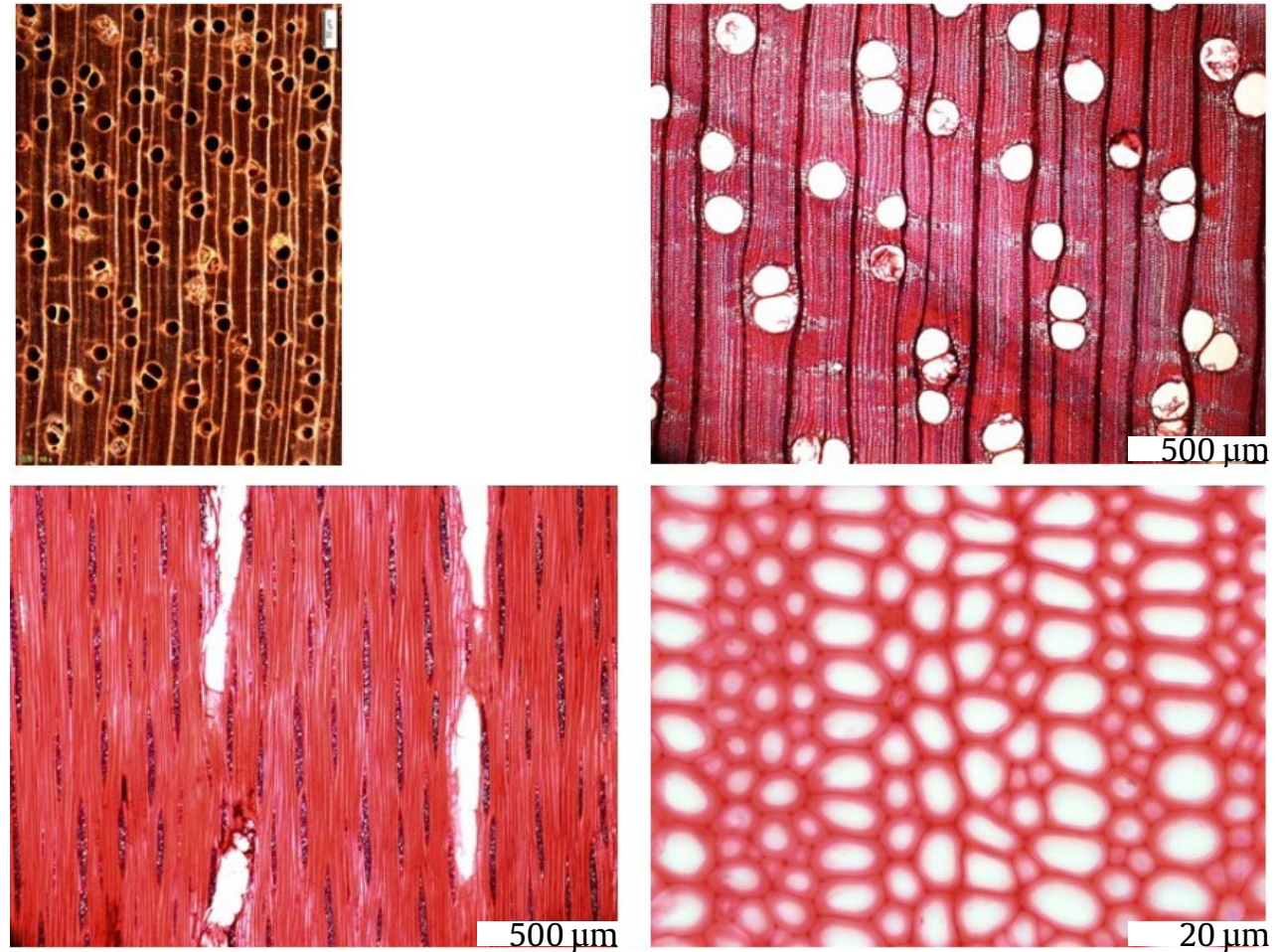

Figure 1. Macroscopic and microscopic sections of White Meranti
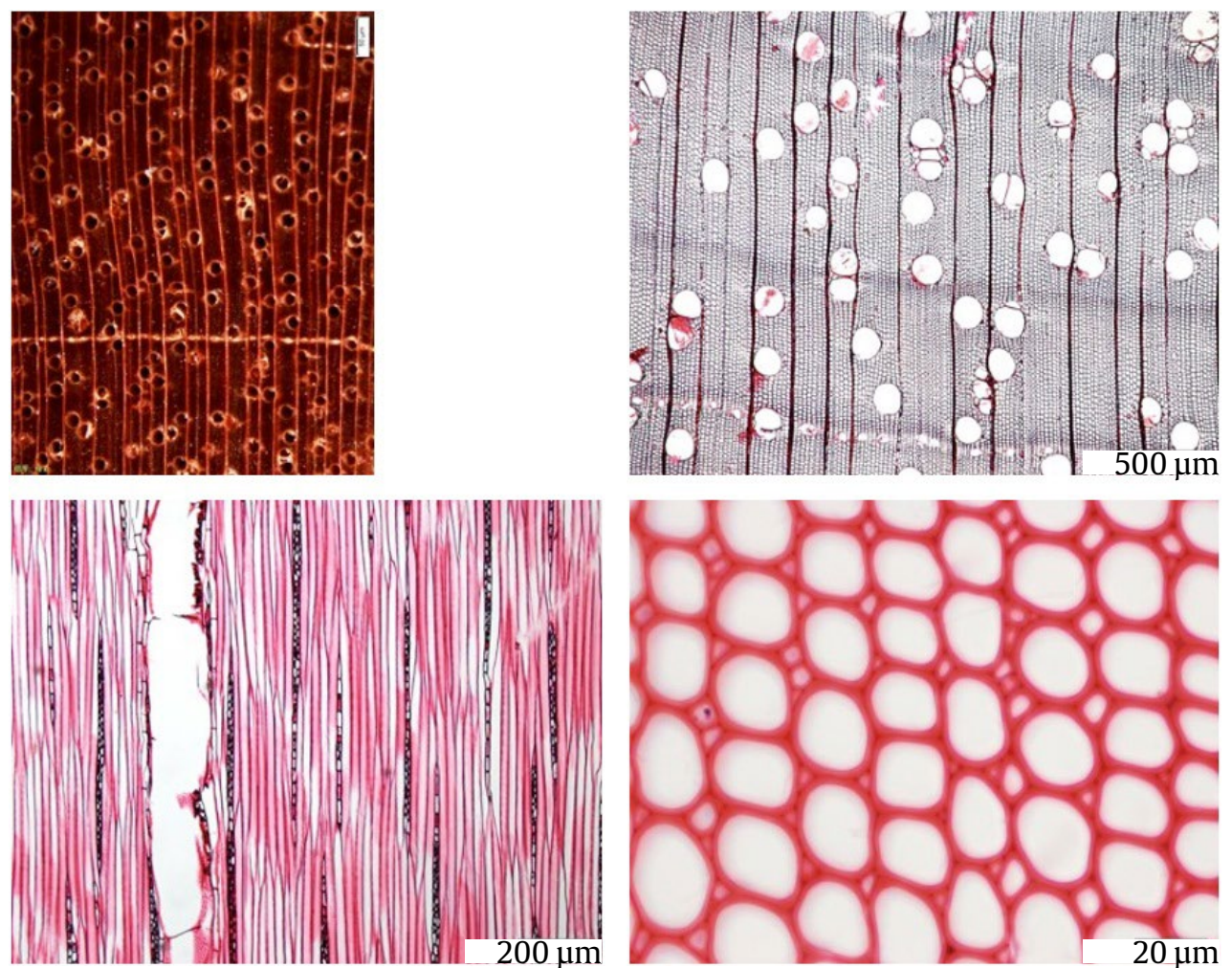

Figure 2. Macroscopic and microscopic sections of Light Red Meranti 

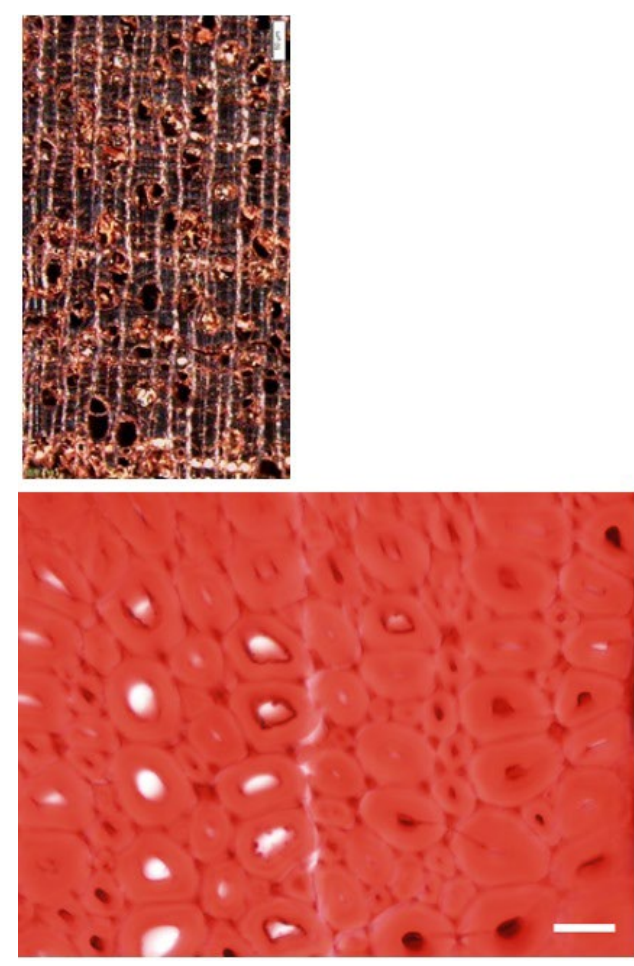

Figure 3. Macroscopic and microscopic sections of Heavy Red Meranti

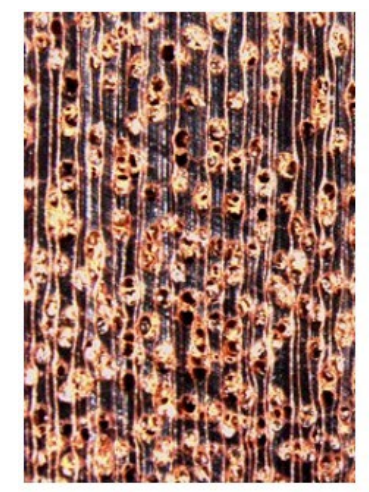

$20 \mu \mathrm{m}$
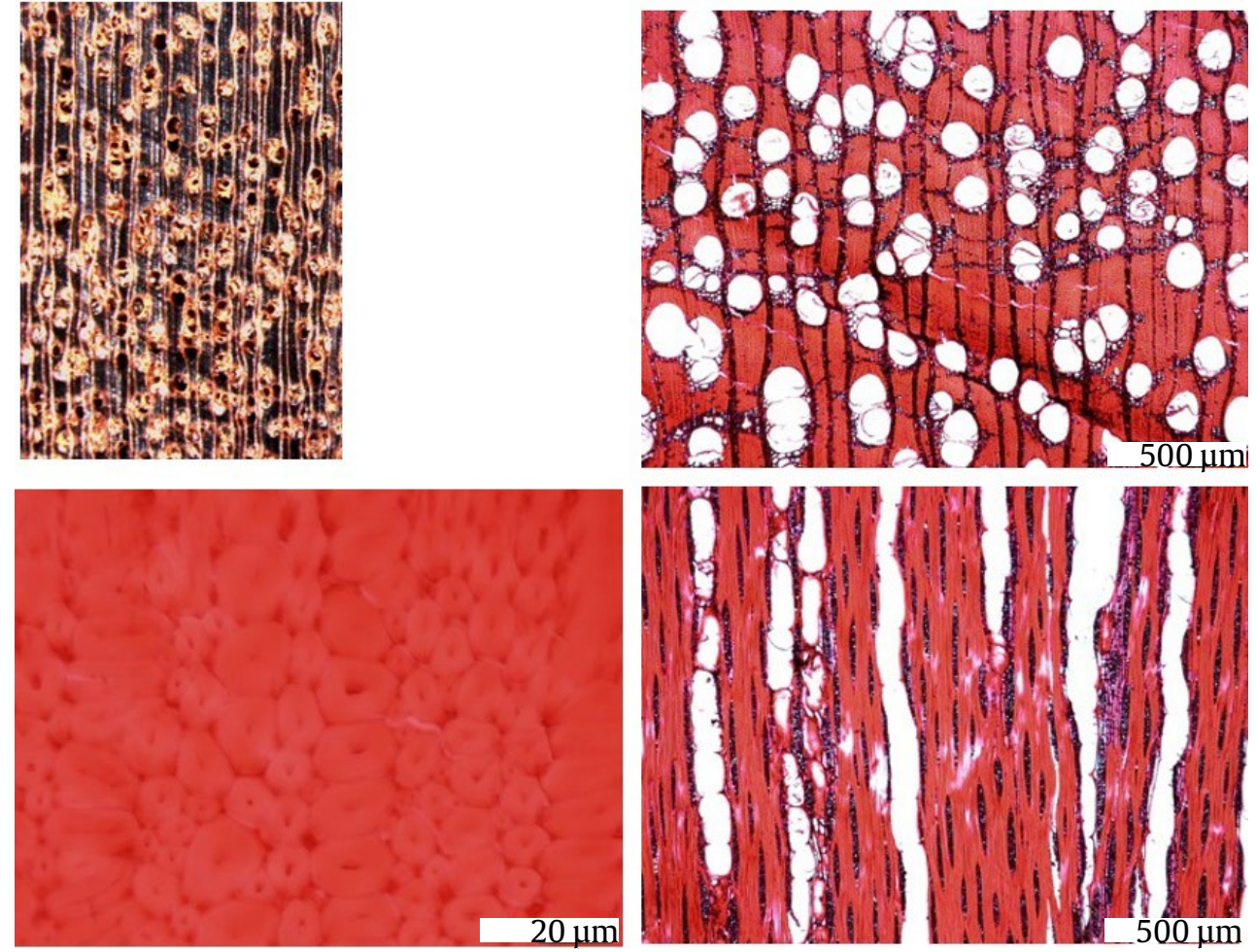

Figure 4. Macroscopic and microscopic sections of Balau
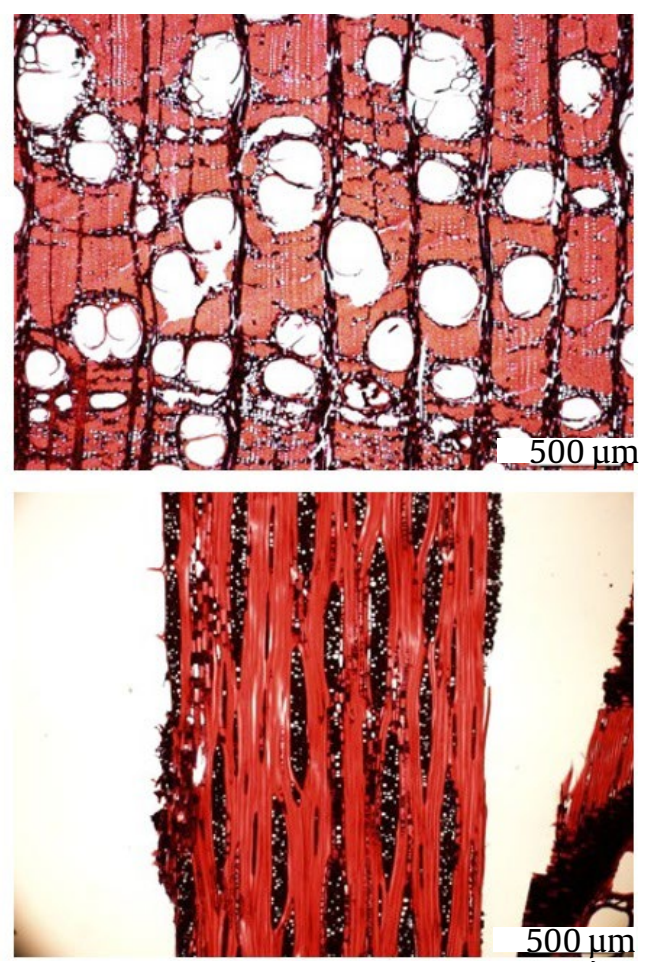


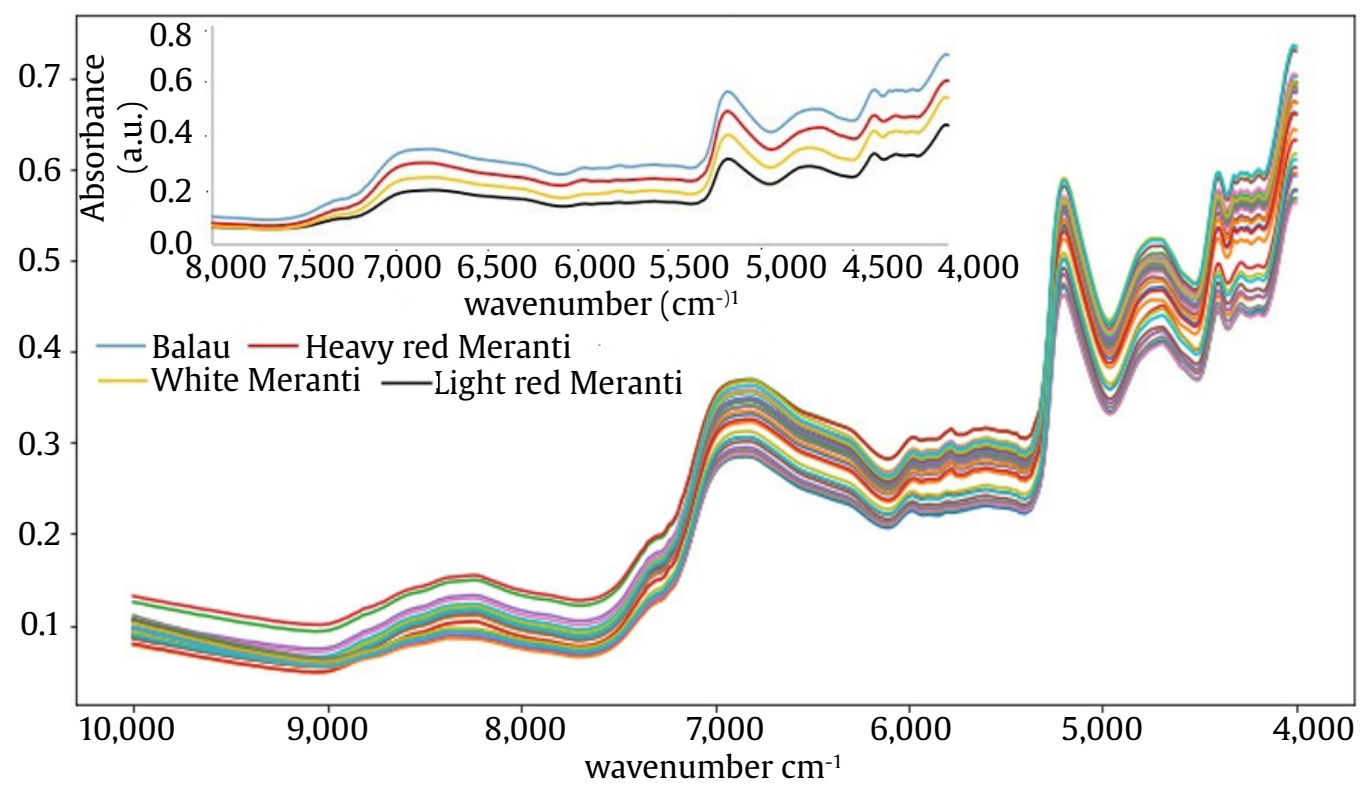

Figure 5. Original spectra of all the samples at wavenumber $10,000-4,000 \mathrm{~cm}^{-1}$

\subsection{PCA Analysis}

The three sub-figures in Figure 6 present the PCA score plot and PC loadings on the first two principal components and the second derivative NIR spectra of the Shorea species in the $8,000-4,000 \mathrm{~cm}^{-1}$ spectral region, respectively. In the score plot, the four Shorea species created their own clusters that were clearly distinguished for both PC1 and PC2 (Figure 6a). PC loading spectra (Figure 6b) provided us with information on which NIR absorption bands contribute to such a clear distinction in the score plot.

Of the twenty spectral regions systematically tested, the $6,200-5,600 \mathrm{~cm}^{-1}$ showed a different aspect from the others. In the PCA score plot in this region, the four Shorea species were clearly clustered (Figure 7a), with high contributions at the $5,800 \mathrm{~cm}^{-1}$ band assigned to furanose or pyranose due to hemicellulose on PC1 and $5,980 \mathrm{~cm}^{-1}$ assigned to aromatic skeletal due to lignin on PC2 (Figure 7b).

\section{Discussion}

White Meranti differ from Red Meranti by their color (whitish-brown) and more numerous vessels (Soerianegara and Lemmens 1994), however, identifying based on the color is not a simple because the color may have changed due to weather, time, environment, etc. In addition, the density is higher, which is $0.54 \mathrm{~g} / \mathrm{cm}^{3}$ compare to $0.27 \mathrm{~g} / \mathrm{cm}^{3}$. Light Red Meranti has a density of 0.25 to $0.45 \mathrm{~g} / \mathrm{cm}^{3}$ (Bosman et al. 1994). Figure 1 and 2 show that the fiber wall of White Meranti was thicker than Light Red Meranti. Moreover, the frequency of the tip cell in the White Meranti was also higher. It indicated that the fiber of
White Meranti might had long of fiber length. Honjo et al. (2006) stated that the greater the frequency of the tip cell, the longer the wood fiber was.

Heavy Red Meranti differ from Balau by its lower density and less numerous rays (Soerianegara and Lemmens 1994). However, Figure 3 shows that rays cell in the Heavy Red Meranti was wider than Balau. The density in this study were $0.64 \mathrm{~g} / \mathrm{cm}^{3}$ and 0.76 $\mathrm{g} / \mathrm{cm}^{3}$, respectively. The wall thickness is believed as one of the factor affect the density. Figure 3 and 4 show that the fiber cell in Balau was thicker (wall thickness) and smaller (diameter) than the Heavy Red Meranti. Even, the lumen of the fiber cell in Balau species was very small and almost closed. Martawijaya et al. (2005) proposed that Balau species has a density between $0.88 \mathrm{~g} / \mathrm{cm}^{3}$ (Shorea sumatrana) to $1.04 \mathrm{~g} / \mathrm{cm}^{3}$ (S. falcifera).

Although conventional method through analysis of anatomical features has been successful to identify the four Shorea wood in this study, this method needs an extra effort to prepare the sample. The result was also take a time. Every Shorea group on the Indonesian timber market has many species, thus, comparing macroscopic and microscopic features of all the group for specific purposes are labour intensive. This study was conducted with limited wood sample of every Shorea group to give preliminary information of the wood response when subjected to the NIR spectra.

The original spectra showed baseline difference, but no differentiation according species was seen (Gierlinger et al. 2004). The absorbance characteristics affected by density. It meant the higher the density, the higher the absorbance was (Via at al. 2012). The wood samples with high density has small light scattering patterns 

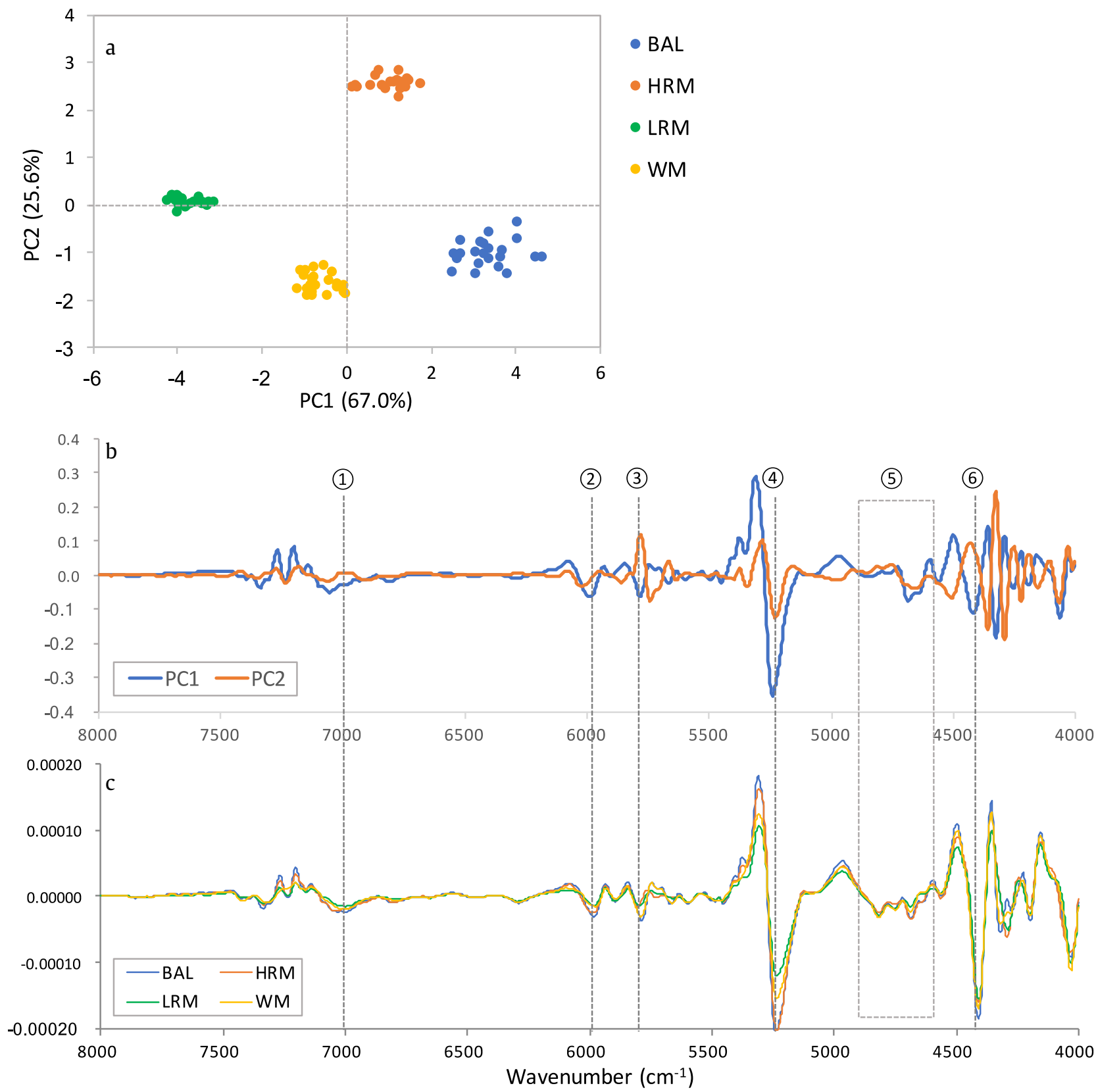

Figure 6. The PCA score plot (a) and loading spectra, (b) of the first two principal components and the second derivative NIR spectra of the four Shorea species, (c) in the $8,000-4,000 \mathrm{~cm}^{-1}$ spectral region. Encircled numbers represent the absorption bands assigned to the major wood components with high PC loading values. (1) $7,000 \mathrm{~cm}^{-1}$, the amorphous regions in cellulose; (2) 5,980 $\mathrm{cm}^{-1}$, aromatic skeletal due to lignin; (3) $5,800 \mathrm{~cm}^{-1}$, furanose or pyranosedue to hemicellulose; (4) 5,220 $\mathrm{cm}^{-1}$, water; (5) 4,890-4,620 $\mathrm{cm}^{-1}$, cellulose; (6) 4,404 $\mathrm{cm}^{-1}$, cellulose and hemicellulose. BAL, Balau; HRM, Heavy Red Meranti; LRM, Light Red Meranti; WM, White Meranti

(Ma et al. 2019). Whereas, in the second derivative spectra (Figure 6c), some differences were revealed at the absorption bands that assigned to representative wood components.

The purpose of PCA is to decompose the data matrix and concentrate the source of variability in the data into first few PCs (Hori and Sugiyama 2003). In addition, it was used to reveal a spectral range that leads to the sharpest low-dimensional projection to find clusters (Gierlinger et al. 2004). We found six absorption bands representing the spectral differences in the second derivative NIR spectra with high PC loading values. PC1 loading showed the highest peak with a negative value at the 5,220 $\mathrm{cm}^{-1}$ band assigned to water. Indeed, this absorption band showed distinct differences between the Shorea species (Figure 8). In the water band (encircled four in 

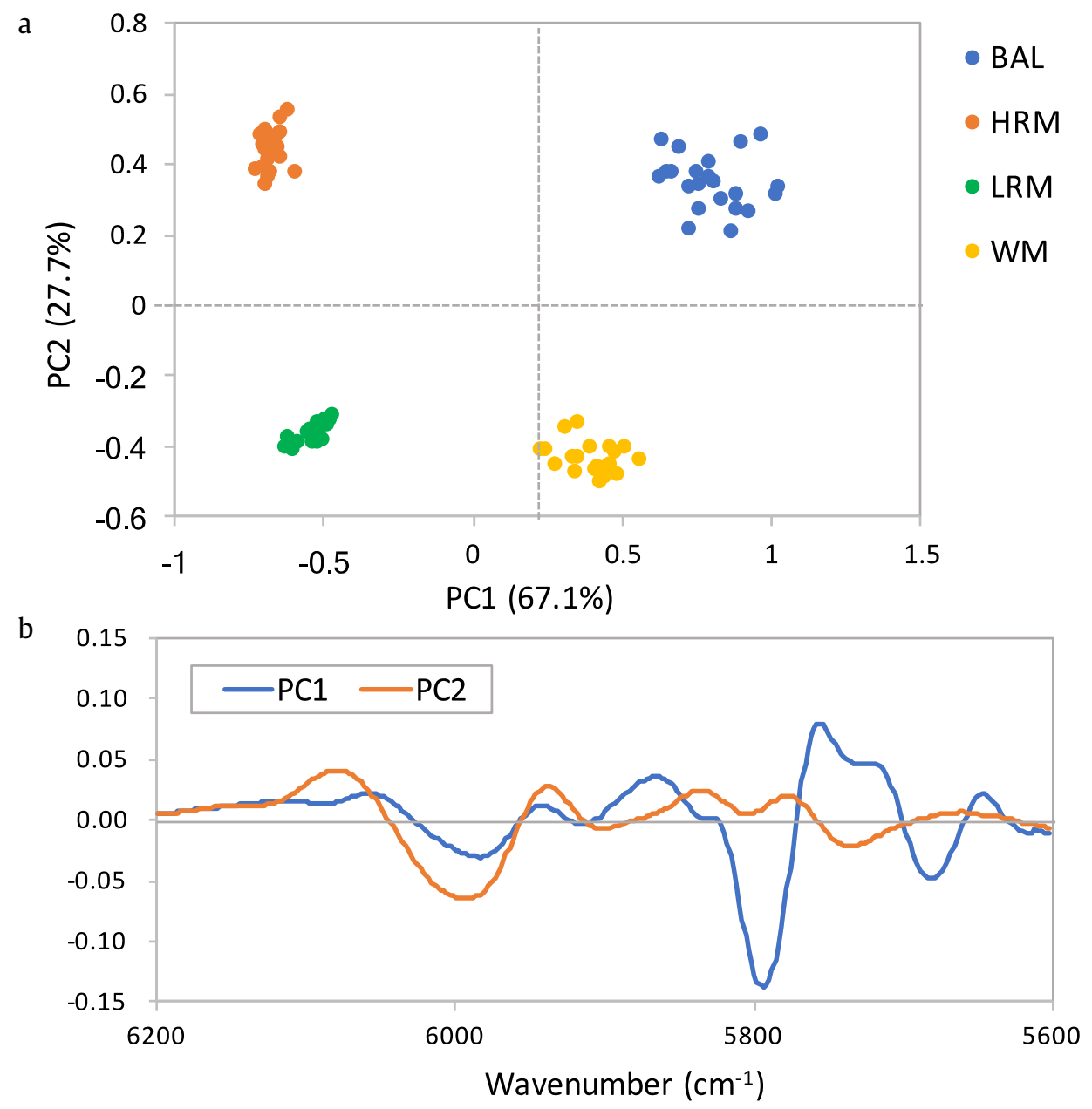

Figure 7. The PCA score plot (a) and loading spectra (b) on the first two principal components in the 6,200-5,600 $\mathrm{cm}^{-1}$ spectral region. BAL:Balau, HRM:Heavy Red Meranti, LRM:Light Red Meranti, WM:White Meranti

Figure 8), Balau and Heavy Red Meranti have stronger peaks than others, which contributed to their position in the positive area for the PC1 axis in the score plot. In this study, we used the second derivative NIR spectra, so the contribution of PC loadings in the score plot was interpreted in the opposite direction for each PC axis. There were some other notable bands, but they were not as dominant as the water.

For PC2 loading, the contribution of the 5,800 $\mathrm{cm}^{-1}$ band assigned to furanose or pyranose due to hemicellulose was prominent with a positive value. In this band, Balau and White Meranti indicated stronger intensity than others (encircled three in Figure 8), which contributed to their position in the negative area for the PC2 axis in the score plot. In addition, absorption bands such as $7,000 \mathrm{~cm}^{-1}$ assigned to amorphous regions in cellulose, $5,980 \mathrm{~cm}^{-1}$ aromatic skeletal due to lignin, $4,890-4,620 \mathrm{~cm}^{-1}$ cellulose, and $4,404 \mathrm{~cm}^{-1}$ cellulose and hemicellulose also showed relatively high values in both PC1 and PC2 loadings.

An interesting aspect that distinguished this short spectral region from others was revealed in the hierarchical clustering analysis. Hierarchical clustering created two sub-clusters in all spectral regions tested. In most regions, including the $8,000-4,000 \mathrm{~cm}^{-1}$, Light Red Meranti and White Meranti formed one cluster, while Heavy Red Meranti and Balau formed another (Figure 9a). Whereas, in the $6,200-5,600 \mathrm{~cm}^{-1}$ region only, two clusters were formed by pairing Light Red Meranti and Heavy Red Meranti, and Balau and White Meranti, respectively (Figure 9b). Although the lignin and hemicellulose-related wood components were the major differences that distinguished the four Shorea species, it was also noteworthy that the clustering result presented in the dendrogram in Figure 9b was consistent with the color similarity between them. In general, wood color was closely related to various extractives. It was not known at the moment, which wood extractives affect the color of the Shorea species, but the dendrogram suggested that wood color-related information may be hidden within the NIR spectral region of $6,200-5,600 \mathrm{~cm}^{-1}$.

The identification result of the Shorea species using the k-NN classifier are presented in Figure 10 as a normalized 

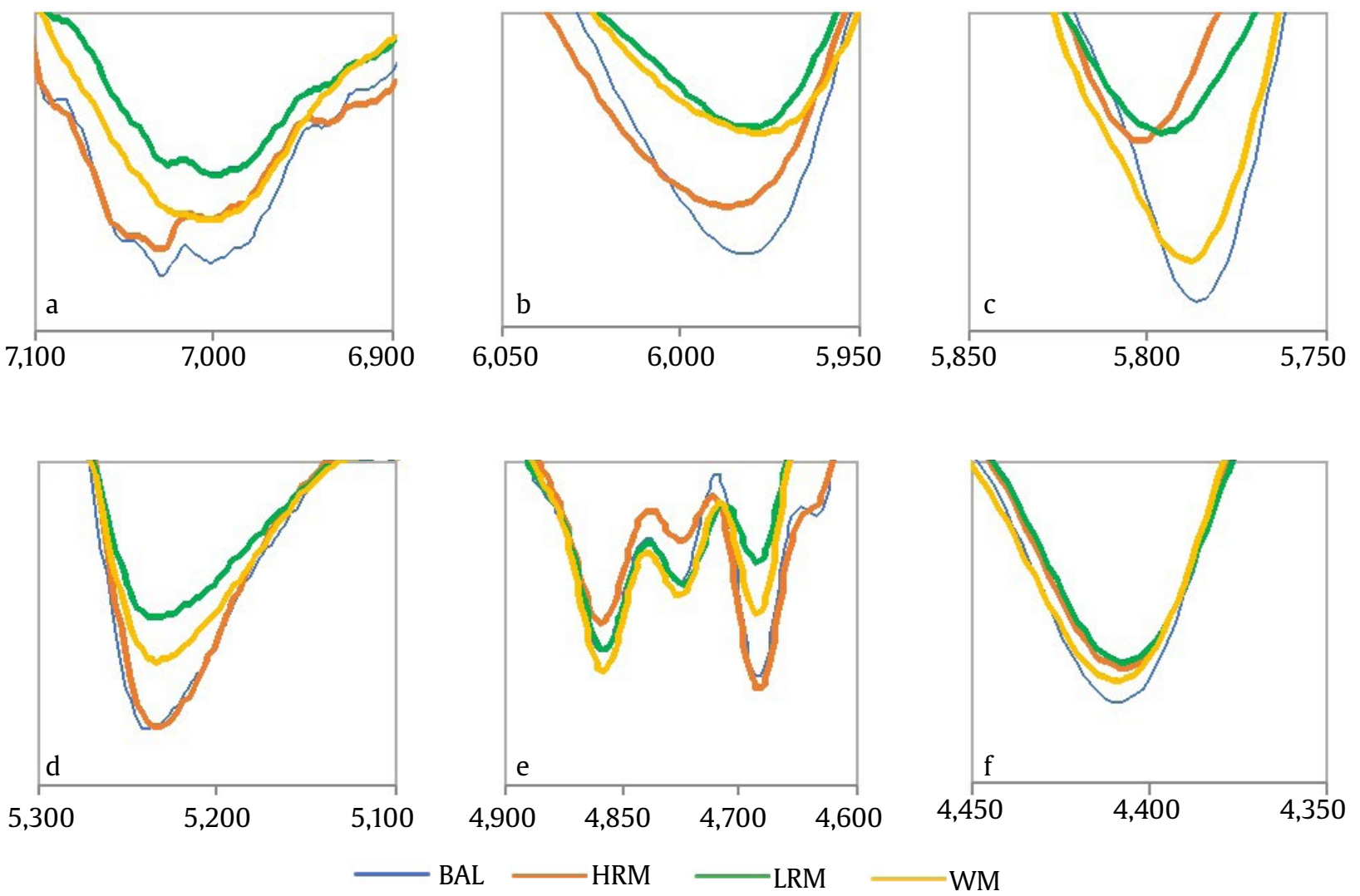

Figure 8. Enlarged spectra of the NIR spectral bands assigned to the major wood components presented in Figure 6. (a) $7,000 \mathrm{~cm}^{-1}$, the amorphous regions in cellulose, (b) $5,980 \mathrm{~cm}^{-1}$, aromatic skeletal due to lignin, (c) $5,800 \mathrm{~cm}^{-1}$, furanose or pyranose due to hemicellulose, (d) $5,220 \mathrm{~cm}^{-1}$, water: (e) 4,890-4,620 $\mathrm{cm}^{-1}$, cellulose: (f) $4404 \mathrm{~cm}^{-1}$, cellulose and hemicellulose. BAL:Balau, HRM:Heavy Red Meranti, LRM:Light Red Meranti, WM:White Meranti
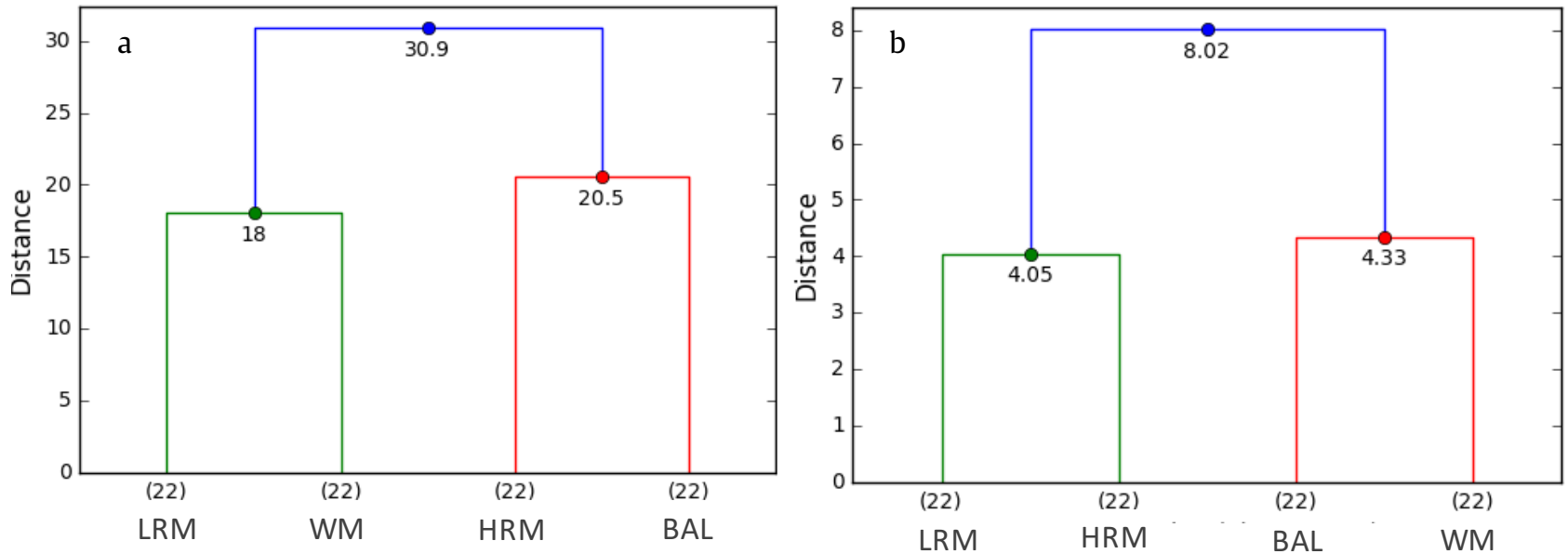

Figure 9. (a) Dendrograms of the four Shorea species in the two NIR spectral regions tested; $8,000-4,000 \mathrm{~cm}^{-1}$, and (b) $6,200-5,600 \mathrm{~cm}^{-1}$. The dendrograms are truncated to the top four cluster levels. The numbers in parentheses are the cluster size and the numbers at the junctions of the branches indicate the Euclidean distance between the clusters. BAL:Balau, HRM:Heavy Red Meranti, LRM:Light Red Meranti, WM:White Meranti 


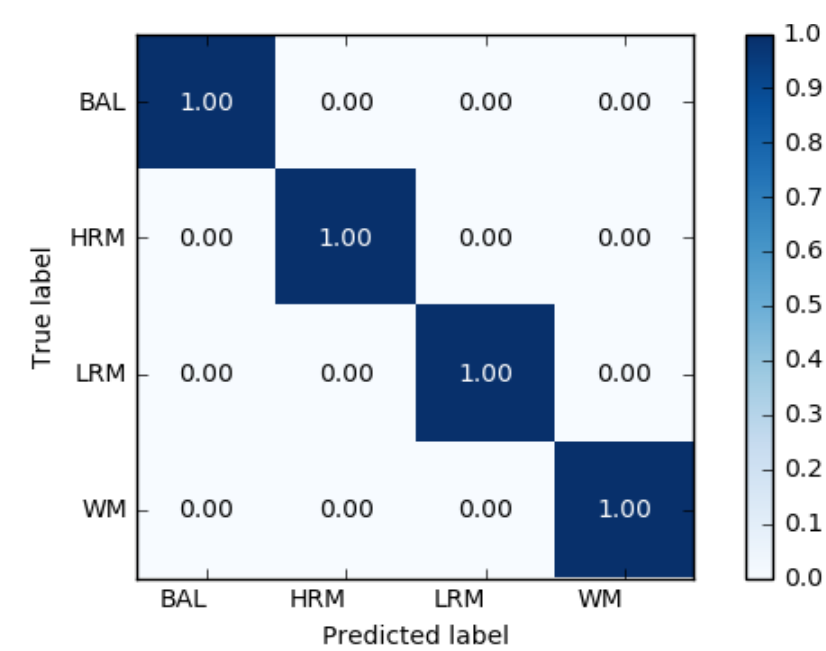

Figure 10. Normalized confusion matrix on the test set in the $\mathrm{k}$-NN classification model $(\mathrm{k}=3)$. The test data are the second derivative NIR spectra with $8,000-4,000 \mathrm{~cm}^{-1}$ spectral region. The k-NN model produced the same result in the 6,200$5,600 \mathrm{~cm}^{-1}$. BAL:Balau, HRM:Heavy Red Meranti, LRM:Light Red Meranti, WM:White Meranti

confusion matrix. The k-NN classification model perfectly identified the Shorea species not only in the 8,000-4,000 $\mathrm{cm}^{-1}$ region but also in the $6,200-5,600 \mathrm{~cm}^{-1}$ region. As confirmed in the PCA results, the four Shorea species had significantly different characteristics in the NIR spectra. Since the possibility of Shorea identification based on chemical composition has been demonstrated from this study, the NIR chemometric approach may complement the conventional identification by visual inspection. The classification model will be more robust if the database contains a wide diversity within and between the Shorea species with a larger number of samples.

\section{Conclusion}

The macroscopic features of the Balau in this study was closely like Heavy Red Meranti, while the White Meranti was almost similar to the Light Red Meranti. At the microscopic level, all of the species have diffuse porous and axial canals in tangential lines. These are common properties in the genera of Shorea, thus, identification and classification of the Shorea wood was not easy. The highest density of the wood was Balau, followed by Heavy Red Meranti, White Meranti, and Light Red Meranti, respectively. The cell wall thickness and lumen diameter of the fiber were the factors, which affects the density. The lumen of fiber cell in Balau was relatively closed, but the opposite result was found in Light Red Meranti.

The characteristics of these species were different when subjected to NIR analyses. The absorbance of the NIR spectra differs considerably among samples. The PCA analysis from two different spectral regions of $8,000-4,000 \mathrm{~cm}^{-1}$ and $6,200-5,600 \mathrm{~cm}^{-1}$, was found best in terms of classification of four Shorea species.

As explained, the precise and facile identification method for four commercially important Shorea species using NIR chemometrics was successfully introduced. However, the model was established from only four Shorea species so that it should be considered as preliminary. In order to make our model more robust and applicable even in nonprofessional market, it is prerequisite to make a database including a wide variety within and between the Shorea species.

\section{Acknowledgements}

The author (Danang S. Adi) would like to thank to the Ministry of Research, Technology and Higher Education of Indonesia, who give a scholarship for his study at Kyoto University through Research Innovation in Science and Technology Project (RisetPro). Taking data and sending the wood sample to RISH-Kyoto University is also partially supported by Japan-ASEAN Science, Technology and Innovation Platform (JASTIP)" under the activity of the Strategic International Collaborative Research Program (SICORP), sponsored by Japan Science and Technology Agency (JST).

\section{References}

Abe H et al. 2016. Simple separation of Torreya nucifera and Chamaecyparis obtusa wood using portable visible and near-infrared spectrophotometry:differences in light-conducting properties. Journal of Wood Science 62:210-212.

Bosman MTM et al. 1994. Radial variaion in wood properties of naturally and plantation grown light red Meranti (Shorea, Dipeterocarpaceae). IAWA Journal 15:111120.

Decree of The Minister of Forestry. 2003. Decree of The Minister of Forestry of Indonesia No. 163/KptsII/2003. Available at:http://arsip.rimbawan.com/ images/stories/aturan-pdf/163 Kpts-II 2003.pdf. [Data accessed:1 September 2019]

Espinoza JA et al. 2012. The potential use of near infrared spectroscopy to discriminate between different pine species and their hybrids. Journal of Near Infrared Spectroscopy 20:437-447. 
Gierlinger N et al. 2004. Characteristics and classification of Fourier-transform near infrared spectra of the heartwood of different larch species (Larix sp.). Journal of Near Infrared Spectroscopy 12:113-119.

Honjo K et al. 2006. Introduction and verification of a novel method for measuring wood fiber length using a single cross section in Acacia mangium. Trees - Structure and Function 20:356-362.

Horikawa Y et al. 2015. Near-infrared spectroscopy as a potential method for identification of anatomically similar Japanese diploxylons. Journal of Wood Science 61:251-261.

Hwang S et al. 2016. Identification of Pinus species related to historic architecture in Korea using NIR chemometric approaches. Journal of Wood Science 62:156-167.

Lang C et al. 2017. Discrimination of taxonomic identity at species, genus and family levels using Fourier Transformed Near-Infrared Spectroscopy (FT-NIR ). Forest Ecology and Management 406:219-227.

Ma T et al. 2019. Rapid identification of wood species by nearinfrared spatially resolved spectroscopy (NIR-SRS) based on hyperspectral imaging (HSI). Holzforschung 73:323-330.

Martawijaya A et al. 2005. Atlas kayu Indonesia Jilid I. Balai Penelitian dan Pengembangan Kehutanan. Departemen Kehutanan.

Miranda et al. 2011. Wood properties of teak (Tectona grandis) from a mature unmanaged stand in East Timor.Journal of Wood Science 57:171-178.

Panshin AJ, de Zeeuw C. 1980. Textbook of Wood Technology. Structure, identifi-cation, properties, and uses of the commercial woods of the United States and Canada. 4th ed. New York:Mc Grw-Hill Company.

Pastore TCM et al. 2011. Near infrared spectroscopy (NIRS) as a potential tool for monitoring trade of similar woods: Discrimination of true mahogany, cedar, andiroba, and curupixá. Holzforschung 65:73-80.
Ramalho FMG et al. 2018. Rapid discrimination of wood species from native forest and plantations using near infrared spectroscopy, Forest System 27:e008. DOI: $10.5424 / \mathrm{fs} / 2018272-12075$

Savitzky A, Golay M J E 1964. Smoothing and differentiation of data by simplified least squares procedures. Anal Chem 36:1627-1639.

Schwanninger $\mathrm{M}$ et al. 2011. A review of band assignments in near infrared spectra of wood and wood. J Near Infrared Spectroscopy 19:287-308.

Soerianegara I, Lemmens RHMJInRHM. 1994. Prosea, plant resources of South-East Asia 5. Lemmens (Eds.). Timber trees: Major commercial timbers. Prosea, Bogor.

Statistics of Forestry Production. 2017. Statistics of Forestry Production 2017. BPS-Statistics Indonesia. Available at:www.bps.go.id/publication/download [Date accessed: 29 August 2019]

Tsuchikawa S, Kobori H. 2015. A review of recent application of near infrared spectroscopy to wood science and technology. Journal of Wood Science 61:213-220.

Tsuchikawa S et al. 2003. Discriminant analysis of woodbased materials using near-infrared spectroscopy. Journal of Wood Science 49:275-280.

Via B et al. 2012. Nonlinear multivariate modeling of strand density from near-infrared spectra. Wood Science and Technology 46:1073-1084.

Wheeler EA. 1989. Iawa List of Microscopic Features for Hardwood Identification. Iawa Bulletin (Vol. 10). Leiden: IAWA.

Yang et al. 2015. Preliminary investigation into the identification of wood species from different locations by near infrared spectroscopy. BioResources 10: 85058517. 